\title{
SANITASI DAN HYGIENE PADA PENGOLAHAN TUNA LOIN BEKU DI PT. HARTA SAMUDRA KABUPATEN PULAU MOROTAI
}

\author{
Titien Sofiati, Iswandi Wahab, Siti Nurbaya Deto \\ Program Studi Teknologi Hasil Perikanan, Fakultas Perikanan dan IImu \\ Kelautan Universitas Pasifik Morotai, Maluku Utara, Indonesia \\ E-mail: titien_sofiati@yahoo.com
}

Received February 2020, Accepted June 2020

\begin{abstract}
ABSTRAK
Salah satu produk olahan tuna di Kabupaten Pulau Morotai yang telah mencapai pasar internasional adalah tuna loin beku yang diproduksi oleh PT. Harta Samudra. Kondisi sanitasi dan hygiene pada proses produksi menjadi penentu keamanan produk. Tujuan dari penelitian ini adalah mengkaji penerapan sanitasi dan hygiene pada pengolahan tuna loin beku di PT. Harta Samudra. Penelitian dilakukan pada bulan November sampai bulan Desember 2019. Pengambilan data di lapangan terbagi dalam dua tahap yaitu survey dan pengambilan data primer yang terdiri dari wawancara, pengisian kuesioner, dan ikut dalam proses produksi serta data sekunder berupa SSOP PT. Harta Samudra. Data dianalisis secara deskriptif dan studi literature. Hasil penelitian menunjukan bahwa aspek sanitasi dan hygiene yang diamati antara lain: personal hygiene pekerja, sanitasi dan hygiene bahan baku, sanitasi dan hygiene air dan es, sanitasi dan hygiene perlengkapan dan peralatan, sanitasi dan hygiene ruang pengolahan, sanitasi dan hygiene produk akhir, serta sanitasi dan hygiene limbah. Hasil kajian menunjukan bahwa pengolahan tuna loin beku di PT. Harta Samudra sangat memperatian sanitasi dan hygiene berdasarkan standar yang telah ditetapkan dalam SSOP.
\end{abstract}

Kata Kunci : Sanitasi, Higiene, Tuna Loin Beku, PT. Harta Samudra

\section{ABSTRACT}

\begin{abstract}
SANITATION AND HYGIENE FOR FREEZED LOIN TUNA PROCESSING AT PT. HARTA SAMUDRA, MOROTAI ISLAND DISTRICT. One of the refined Tuna product in Morotai Island Regency that have reached International Markets is freezing loin tuna was producing by PT. Harta Samudra. The sanitary and hygienist of the producing process become the determinant of product's safety. The purpose of this research is to study the sanitary and hygiene application on the Processing at PT. Harta Samudra. The research has done from November to December 2019. The collecting data is filed divide into two steps, which is survey and collecting the primary data from interview, filling questionnaires, and following the production process, also the SSOP of
\end{abstract}


PT. Harta Samudra as the secondary data. The data analysis in descriptive and literature study ways. The research results shows that the sanitary and hygiene aspects that observed, there were: personal hygiene worker, sanitary and hygiene of materials, sanity and hygiene of water and ice, sanitary \& hygiene of the tools, sanitary and hygiene of processing room, sanity and hygiene final product, also sanitary and hygiene of waste. The final study showed that the processing of freezing loin tuna at PT. Harta Samudra was really taking care of the sanitary and hygiene based on the SSOP standard.

Keywords : Sanitary, Hygiene, Frezzing Loin Tuna, PT. Harta

\section{PENDAHULUAN}

Tuna adalah ikan yang bernilai ekonomis penting di Indonesia. Potensi tuna di Kabupaten Pulau Morotai pada tahun 2017 sebesar 496 ton (BPS Kabupaten Pulau Morotai. 2018). Kementrian Kelautan Perikanan (2019), mengemukakan bahwa tuna tongkol dan cakalang (TCT) merupakan komoditas penyumbang nilai ekspor perikanan indonesia setelah udang. Sumberdaya ikan yang potensial ini menjadikan Kabupaten Pulau Morotai menjadi daerah yang kaya jika dapat memanfaatkan tuna secara optimal.

Pemanfaatan tuna di Kabupaten Pulau Morotai meliputi; dijual mentah langsung ke konsumen dan diolah menjadi produk olahan. Produk olahan tuna antara lain tuna asap, abon tuna, bakso tuna, kaki naga tuna, dan tuna loin beku. Produk olahan tuna tersebut dipasarkan di pasar lokal dan nasional. Khusus untuk tuna loin, produk ini sudah menembus pasar internasional.

Tuna loin beku merupakan salah satu produk olahan ikan tuna. sifat alami ikan yang mudah busuk mengharuskan bahan baku ini di tangani dengan baik selama proses produksi. Produk tuna loin yang berstandar internasional ini diproduksi oleh PT. Harta Samudra. PT. Harta Samudra Morotai merupakan salah satu perusahaan yang bergerak dibidang pengolahan hasil perikanan dengan produk tuna loin beku. Hasil produksi tuna loin beku PT. Harta Samudra sudah dipasarkan ke beberapa negara yaitu Jepang, Vietnam dan Amerika.

Sanitasi dan hygiene merupakan salah satu faktor penting yang harus diperhatikan demi menjamin keamanan panngan. Apabila dalam suatu produk tidak di perhatikan sanitasi dan hygiene pada proses produksi akan menghasilkan produk yang tidak lulus mutu atau layak dikonsumsi. Domili (2017) mengemukakan bahwa penerapan sanitasi dan hygiene yang kurang baik pada pengolahan makanan dapat menimbulkan hal-hal yang merugikan konsumen, seperti keracunan maupun penyankit yang tertular melalui makanan. Oleh karena itu penerapan sanitasi dan hygiene pada pengolahan produk tuna loin beku di PT. Harta Samudra perlu untuk dikaji. 


\section{MATERI DAN METODE}

\section{Tempat dan Waktu Penelitian}

Penelitian dilaksanakan di PT. Harta Samudra Desa Daeo Majiko Kecamatan Morotai Selatan Kabupaten Pulau Morotai. Lokasi penelitian dapat dilihat pada Gambar 2. Waktu penelitian dilaksanakan selama bulan November-Desember 2019 dalam 2 tahap. Tahap pertama yaitu survey lokasi penelitian, dan tahap kedua yakni pengambilan data dilapangan.

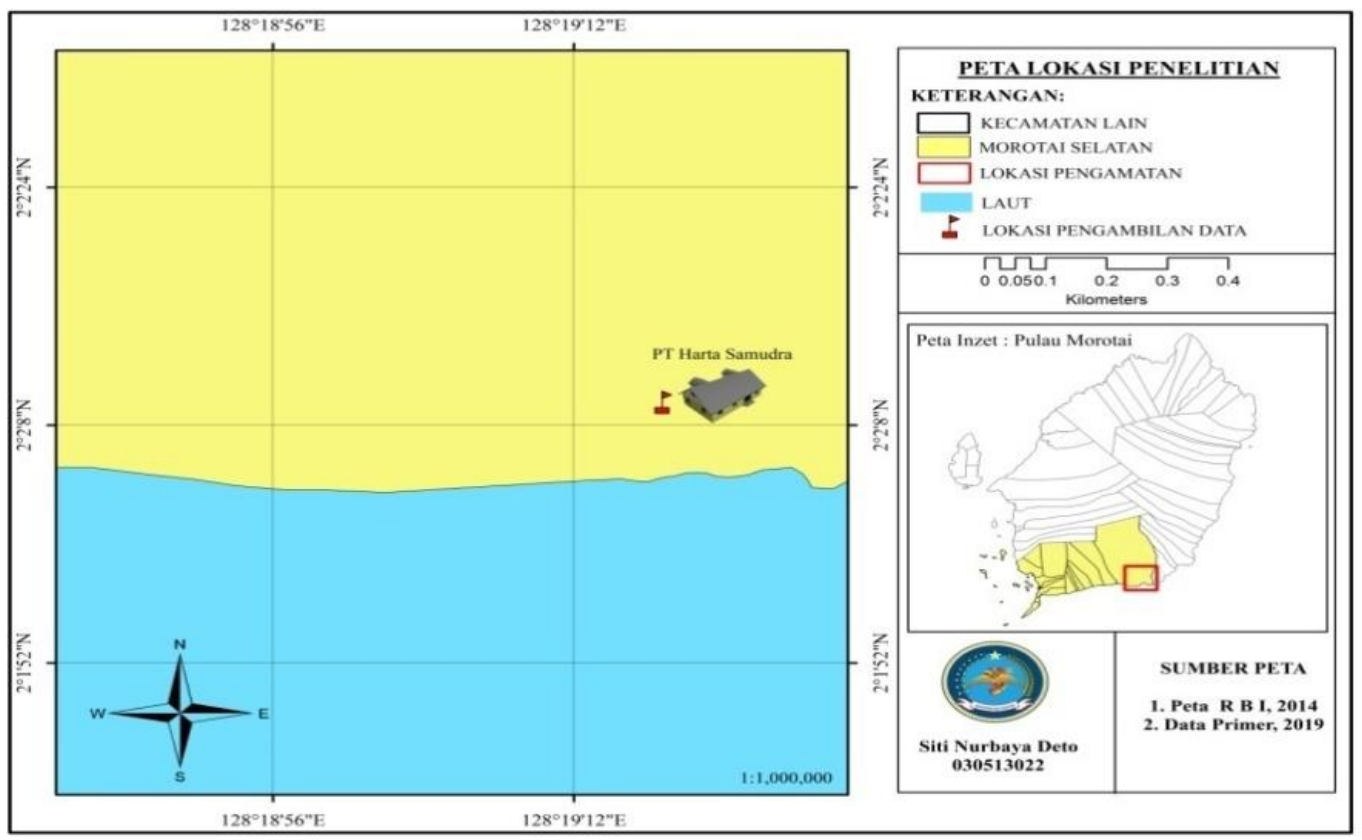

Gambar 1. Peta lokasi penelitian

Penentuan lokasi penelitian didasarkan pada pertimbangan bahwa PT. Harta Samudra merupakan satu-satunya perusahaan pengolah tuna loin beku di morotai yang telah melakukan ekspor ke luar negeri. Alat dan bahan yang digunakan terdiri dari alat tulis, kuesioner, dan kamera.

\section{Prosedur Pengambilan Data}

Survey lokasi dilakukan dengan pengamatan langsung di lapangan sekaligus meminta kesediaan perusahaan untuk diikutsertakan mengikuti dan melakukan salah satu proses produksi tuna loin beku. pengamatan di lapangan meliputi pengenalan fasilitas-fasilitas perusahaan, fasilitas sanitasi, dan pengamatan keberhihan pekerja. Pengambilan data di lapangan dilakukan dengan pengisian kuesioner, wawancara, mengikuti proses produksi dan pengumpulan data sekunder. Pengisian kuesioner dan wawancara semi terstruktur terhadap karyawan PT. Harta Samudra. Jumlah karyawan yang diwawancarai sebanyak 13 orang, 12 orang diantaranya pekerja dan 1 orang yang merupakan qualty control (QC). Data sekunder yang diperoleh adalah SSOP PT. Harta Samudra. 


\section{Analisis Data}

Analisis data sanitasi dan higiene pada pengolahan tuna loin beku dilakukan secara deksriptif dan pemaparan hasil penelitian didukung dengan studi literatur dan data sekunder.

\section{HASIL DAN PEMBAHASAN}

\section{Gambaran Umum Lokasi Penelitian}

Perusahan PT. Harta Samudra berada dikawasan Sentral Kelautan Dan Perikanan Terpadu (SKPT) yang terletak di Desa Daeo Majiko, Kecamatan Morotai Selatan, Kabupaten Pulau Morotai, Provinsi Maluku Utara. Lokasi perusahaan ini memiliki letak yang strategi. Sebelah selatan berbatasan dengan Desa Daeo induk, sebelah utara berbatasan dengan Desa Sambiki Baru, sebelah barat berbatasan dengan Jln. Daruba-Daeo $\mathrm{km} 26$ Sebelah timur berbatasan dengan laut.

Perusahan PT. Harta Samudra Morotai merupakan perusahan yang bergerak dalam bidang pengolahan hasil perikanan dengan produk tuna loin beku. Perusahan PT. Harta Samudra memiliki beberapa cabang lain seperti di Ambon, Dobo, dan Morotai. Proses pengolahan dimulai pada tahun 2018 yang diekspor ke negara Vietnam dengan produk tuna loin beku. Selain mengekspor ikan tuna ke luar negeri, PT. Harta Samudra juga satu-satunya perusahan yang bermitra dengan pemerintah Kabupaten Pulau Morotai dan juga menjual produk dipasar lokal. Produk yang di jual di pasar lokal adalah bagian tubuh yang tidak di ambil dari pembuatan loin (Limbah). Limbah dari produksi ini di kenal masyarakat dengan tetelan.

\section{Proses Produksi Tuna Loin Beku}

Sofiati dan Deto (2019), mengemukakan bahwa proses produksi tuna loin beku di PT. Harta Samudra terdiri dari 18 tahap. Proses pengolahan dimulai dari penerimaan bahan baku hingga pada proses pemuatan/stuffing ke konsumen. Adapun alur produksi tuna loin beku di PT. Harta Samudra dapat di lihat pada Gambar 2 berikut.

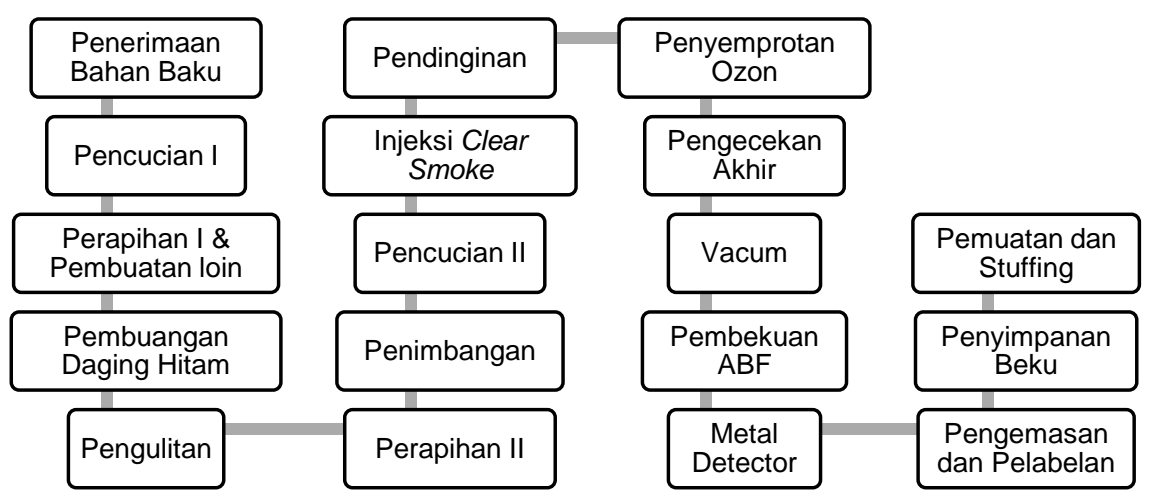

Gambar 2. Alur produksi tuna loin beku di PT. Harta Samudra 


\section{Personal Higiene Pekerja}

Penanggung jawab pengendalian personal hygiene pekerja di ruang proses produksi PT.Harta Samudera yaitu staf bagian produksi dan staf Quailty control (QC). Tugas dari staf produksi dan QC yaitu untuk memastikan pekerja dan ruang produksi berada dalam kondisi yang bersih berdasarkan Standard Sanitation Operating Procedure (SSOP). Pengendalian hygiene pekerja dilakukan dengan melakukan pengecekan rutin dan pengecekan perlengkapan pekerja. Pengecekan rutin pekerja dilakukan sebelum pekerja masuk ke ruang produksi. Pengecekan kebersihan meliputi kuku, kumis, tangan, make up (khusus untuk pekerja wanita) dan perlengkapan pekerja.

Perlengkpan pekerja PT. Harta samudra pada proses produksi tuna loin beku terdiri dari pakaian pekerja, hairnet atau penutup kepala, sepatu boots, sarung tangan, masker dan celemek (untuk pekerja dibagian pemotongan dan pencucian). Elston (2007) dalami Ta'sya, (2018) mengemukakan bahwa baju kerja pekerja dibidang pangan harus mampu menutupi seluruh anggota tubuh pekerja yang berpotensi bersentuhan dengan produk. Personal hygiene pekerja dapat dilihat pada Gambar 3.

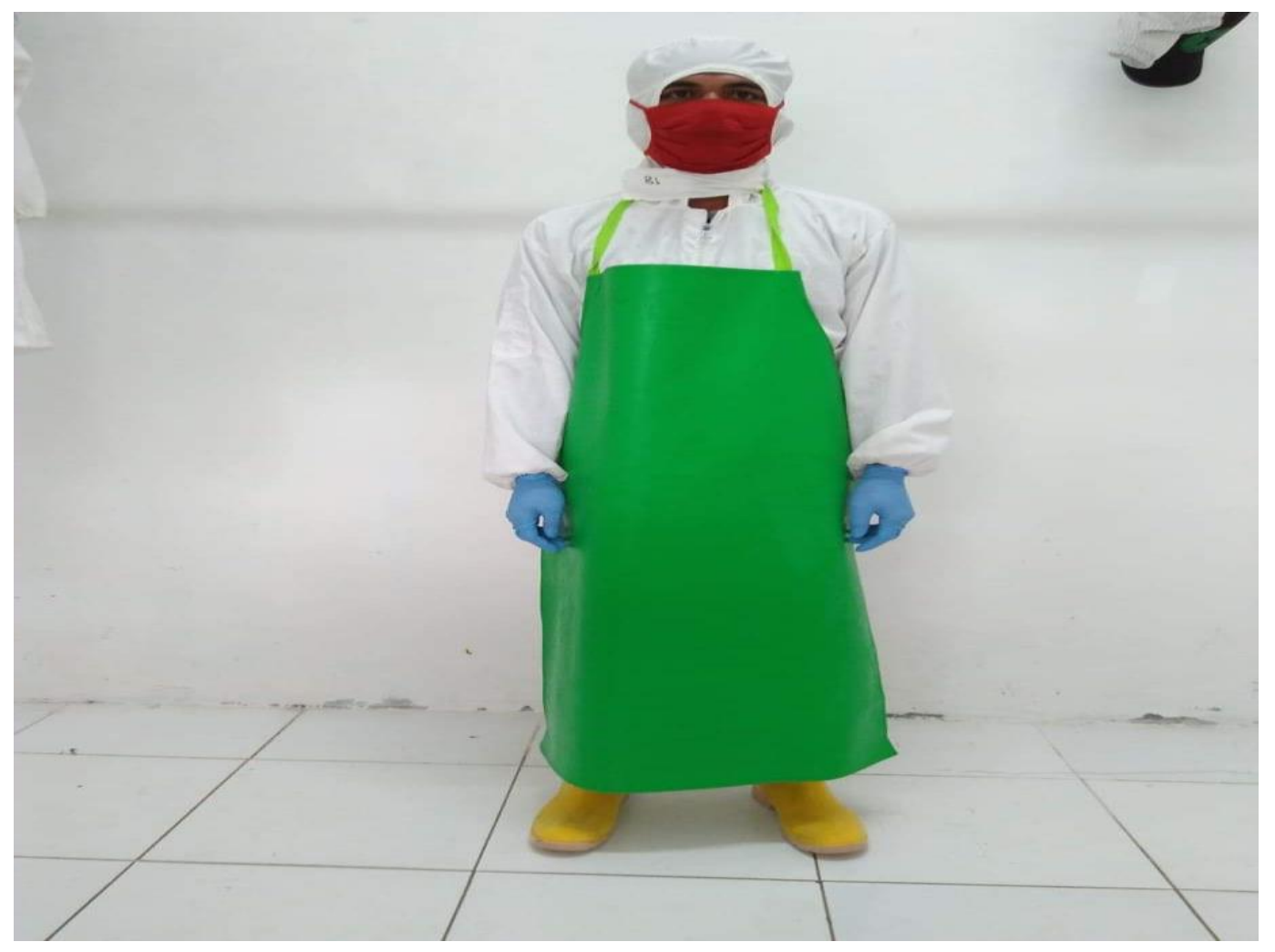

Gambar 3. Personal hygiene pekerja

\section{Sanitasi dan Higiene Bahan Baku}

PT. Harta Samudra lebih mengutamakan dan memperhatikan kebersihan dan mutu ikan yang akan dijadikan sebagai bahan baku. 
Tingkat kesegaran ikan ditentukan melalui uji organoleptic berdasarkan standar yang telah ditentukan oleh perusahaan, termasuk pengecekan suhu tubuh ikan. Sofiati dan Deto (2019), mengemukakan bahwa penanganan awal pada bahan baku yakni mempertahankan suhu tubuh ikan tetap dibawah $4^{\circ} \mathrm{C}$ sehingga tidak meningkatkan kadar histamine. Ikan yang memiliki kadar histamine yang tinggi, jika dikonsumsi oleh manusia akan menimbulkan penyakit alergi (Damongilala. 2009).
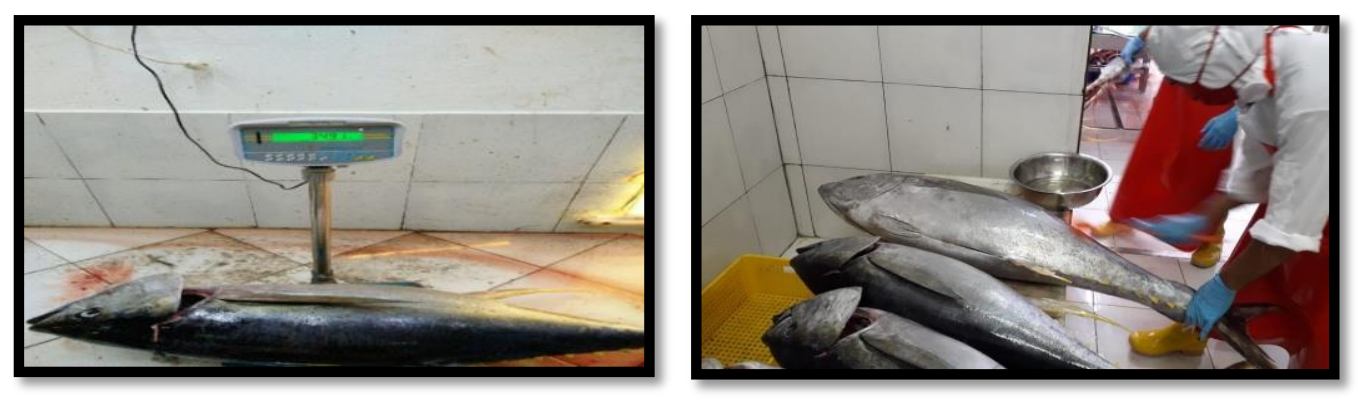

Gambar 4. Penanganan bahan baku

\section{Sanitasi dan Higiene Air dan Es}

Air merupakan factor penting dalam pengolahan tuna loin beku di PT. Harta Samudra. Penggunaan air diperuntukan pada proses produksi (tahap pencucian), bahan dasar untuk es, dan sebagai pembersih tempat produksi. Thaheer (2005) mengemukanan bahwa air dalam penanganan pangan terdiri dari air pengolahan, air minum, dan air bersih. Faktor yang menjadi perhatian yaitu sumber air yang digunakan pada proses produksi maupun pembuatan es harus memenuhi standar air bersih yang terhindar dari kontaminasi bakteri maupun bahan kimia. Hal ini sesuai dengan Purnawijayanti (2001), yang mengemukakan bahwa air yang digunakan dalam pengolahan makanan harus memenuhi syarat: bebas dari bakteri, bebas dari ketidakmurnian kimiawi, bersih dan jernih, tidak berbau, dan tidak mengandung bahan tersuspensi. PT. Harta Samudra melakukan pengujian kualitas air setiap 6 bulan sekali dilabolatorium terakreditasi yaitu di labolatorium PT. Seafood Inspection Laboratory Bali untuk menjamin kebersihan air yang digunakan.

\section{Sanitasi dan Higiene Perlengkapan dan Peralatan}

PT. Harta Samudra sangat memperhatikan sanitasi dan hygiene alat produksi, karena alat produksi merupakan salah satu sumber kontaminasi bakteri. Alat produksi yang digunakan berbahan dasar stainles stel dan plastik. Alat produksi yang berbahan stainles yaitu meja dan pisau, sedangkan alat produksi yang berbahan plastik yaitu keranjang, gayung, sikat wiper dan sikat. Berdasarkan SSOP PT. Harta samudra, dalam menjaga kebersihan perlengkapan dan peralatan produksi dilakukan beberapa langkah. Peralatan yang digunakan dalam proses pengolahan harus dibersihkan sebelum dan sesudah proses oleh para pekerja. 
Baskom, keranjang, gayung, dan peralatan lain harus dibersihkan dan disikat dengan menggunakan sabun, kemudian dibilas dengan air bersih. peralatan yang memiliki sifat korosif pencucian dilakukan dengan menggunakan klorin. Penggunaan klorin berkonsentrasi rendah, yaitu sebesar 50-100 mg/1 dalam waktu 10-20 menit sebelum digunakan (Huss et al.,2004).

\section{Sanitasi dan Higiene Ruang Pengolahan}

Ruang pengolahan merupakan tempat yang penting dalam proses produksi di PT. Harta Samudra. Hal ini dikarenakan pada ruang inilah semua proses produksi dilakukanan, sehingga sanitasi dan hygiene sangat diperhatikan untuk menjamin kebersihan produk akhir. Ruangan pengolahan ini terdiri dari ruangan penerimaan, ruang pencucian, ruang cutting, ruang trimming, unit refrigerasi (chilling room, 2 air blast freezer dan cold storage) yang diberi batas yang jelas. Sanitasi dan hygiene bangunan sudah sangat diperhatikan, dinding terbuat dari tembok, lantai keramik sehingga memudahkan untuk dibersihkan.

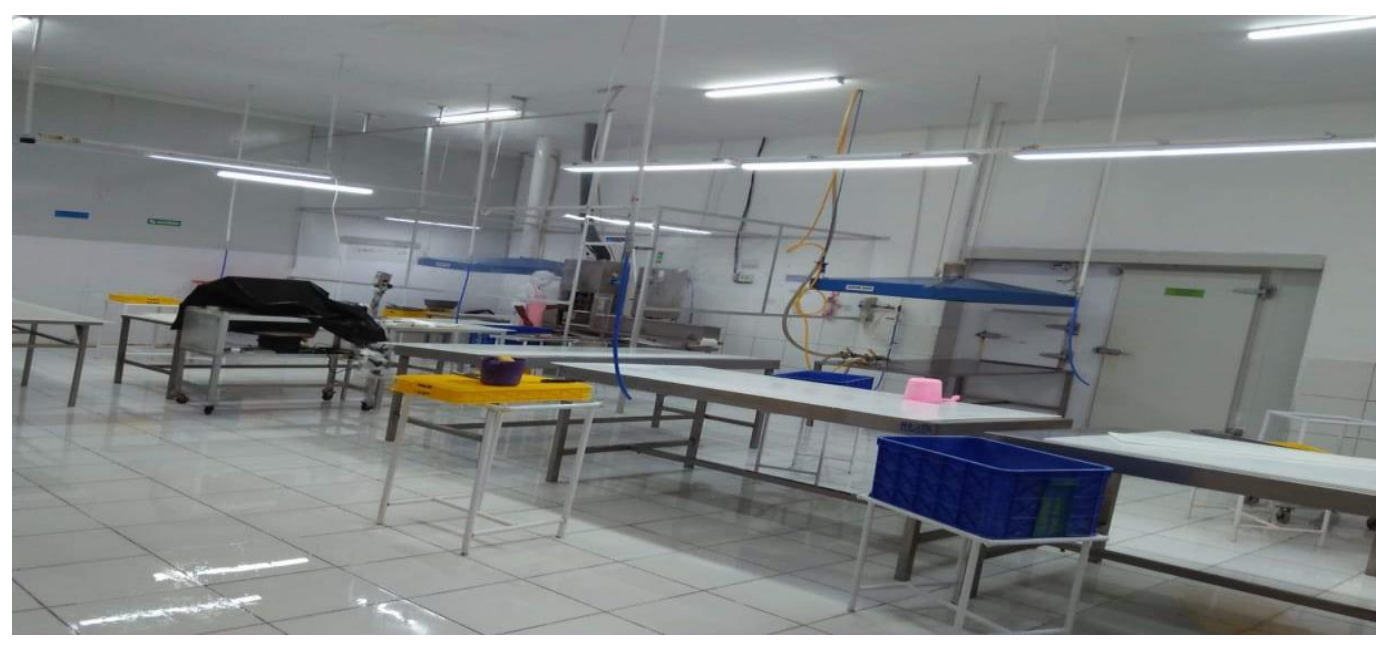

Gambar 5. Ruang Pengolahan

Sanitasi dan hygiene Peralatan yang ada di ruang pengolahan tak luput dari perhatian. Peralatan yang terdapat dalam ruang produksi terdiri dari meja, keranjang, pisau, gayung, timbangan digital, mesin injeksi, mesin vacum, dan selang. Alat tersebut harus dibersihkan dengan menggunakn air bersih yang sudah direkomendasi oleh pihak perusahaan agar lebih menjaga kebersihan peralatan. Menurut DKP (2007) permukaan bahan yang kontak dengan produk dibagian pengolahan harus terbuat dari bahan tahan karat, sehingga mudah dibersihkan. Adanya debu, tetesan air, dan pergerakan udara dari gerak angin atau manusia dapat mempengaruhi kondisi udara di tempat persiapan makanan (pengolahan pangan) (Sari. 2004).

Para pekerja yang akan melakukan proses produksi sebelum masuk ke ruang pengolahan sudah dalam keadaan saniter guna mencegah 
terjadinya kontaminasi silang. Kontaminasi silang merupakan kontaminasi yang terjadi antara pekerja dan produk. Kontaminasi akan dengan mudah terjadi apabila pekerja tidak memperhatikan kebersihan dalam proses pengolahan yang mungkin saja berasal dari peralatan. Berdasarkan SSOP PT. Harta Samudra, sanitasi dan hygiene di semua aspek yang ada di ruang produksi sudah sangat diperhatikan.

\section{Sanitasi dan Higiene Produk Akhir}

Produk akhir pengolahan tuna loin beku PT. Harta Samudra melewati beberapa tahap pengolahan dan terkontrol sanitasi dan higienenya. Demi mendapatkan hasil yang baik dan bersih produk tersebut harus dikemas sebaik mungkin agar kemasan yang digunakan benar-benar aman dan tidak mempengaruhi mutu dari produk tuna loin beku itu sendiri. Pengemasan dilakukan dengan tujuan agar produk terhindar dari bakteri yang akan menyebabkan kemunduran mutu pada produk tuna loin beku maka secepat mungkin produk itu di kemas dan di simpan diruang penyimpanan dengan suhu ruang yg suda di tentukan yaitu $18^{\circ} \mathrm{C}-25^{\circ} \mathrm{C}$.

\section{Sanitasi dan Higiene Limbah}

Limbah yang dihasilkan dari pengolahan tuna loi beku di PT. Harta Samudra terdiri dari limbah padat dan limbah cair. Limbah padat berupa potongan kepala, ekor, sirip, dan jeroan yang merupakan hasil dari pembuatan loin. Sedangkan limbah cair yaitu hasil dari proses pencucian yang dilakukan saat proses pengolahan dimulai. Pengendalian sanitasi dan hygiene limbah padat dimasukan kedalam plastik dan diletakan di atas keranjang, agar tidak tercampur dengan loin, Keranjang yang digunakan harus dibersihkan menggunakan sabun sebelum dan setelah digunakan. Limbah cair juga merupakan faktor penyebab timbulnya kontaminasi silang yang sangat tinggi sehingga diperlukan penanganan khusus yaitu dengan fasilitas pembuangan limbah melalui saluran yang terbuat dari pipa besar sehingga pembuangan limbah cair tidak mempengaruhi lingkungan sekitar. Menurut DKP (2007) area pembuangan limbah terpisah, tempat limbah tahan karat, dan dilengkapi dengan tutup, tempat limbah dibersihkan dengan benar, limbah dipindahkan minimal sehari sekali serta tempat penyimpanan limbah tidak berpotensi terjadi kontaminasi.

\section{KESIMPULAN}

PT. Harta Samudra sangat memperhatikan aspek sanitasi dan hygiene dalam pengolahan tuna loin beku. Factor-faktor yang menjadi pusat perhatian yaitu sanitasi dan hygiene bahan baku, air dan es, peralatan dan perlengkapan, ruang pengolahan, produk akhir dan limbah. Pengendalian sanitasi dan hygiene dilakukan berdasarkan SSOP PT. Harta Samudra. 


\section{DAFTAR PUSTAKA}

[BPS] Badan Pusat Statistik. 2018. Kabupaten Pulau Morotai Dalam Angka. CV. Dharmaputra. Jakarta

Domili R S. 2017. Sanitasi dan Hygiene pada Proses Pembuatan Rambak Ikan Buntal Pisang (Tetraodon lunaris) di UKM Jaya Utama Kecamatan Mayangan Kota Kota Probolinggo Jawa Timur. Jurnal Aquabis. 7(2): 1-5

Damongilala L J. 2009. Kandungan Histamin Beberapa Jenis Komoditi Ikan Tuna. Jurnal Perikanan dan Kelautan Unstrat manado. V(3):2023

[DKP] Departemen Kelautan dan Perikanan. 2007. Keputusan Menteri Kelautan dan Perikanan Republik Indonesia No. Kep. 01/Men/2007tentang PersyaratanJaminan Mutu dan Keamanan hasil Perikanan pada Proses Produksi, Pengolahan dan Distribusi. Jakarta : DKP.

[KKP] Kementerian Kelautan dan Perikanan. 2019. Ekspor Tuna Cakalan Tongkol Indonesia 6 Tahun Terakhir (2012-2017), Kondisi dan Harapan. [26 Oktober 2019]. https://kkp.go.id/djpdspkp/artikel/2746ekspor-tuna-cakalang-tongkol-indonesia-6-tahun-terakhir-20122017-kondisi-dan-harapan

Huss HH. Ababoutch L, Gram L. 2004. Assessment and Management Of Seafood Safety and Quality. Roma : FAO.

Purnawijayanti, 2001. Sanitasi Higiene dan keselamatan kerja dalam pengolahan makanan. Jogjakarta: Kanisius

Sari, P. 2004. Sanitasi dan Hygiene Dalam Industri Pangan. Fakultas Teknologi Pertanian. Uiversitas Jember. Jember. Hal 1. 35 dan 108.

Sofiati T, Deto S N. 2019. Profil Pengolahan Tuna Loin Beku di PT. Harta Samudra Kabupaten Pulau Morotai. Jurnal Bluefin Fisheries. 1(2).

Ta'sya T F. 2018. Menejemen personal hygiene pekerja pada produksi loin tuna masak beku di PT.Blambangan Foodpackers Indonesia. [PKL]. Universitas Airlanga Surabaya.

Thaheer H. 2005. Sistem Manajemen HACCP. Bumi Aksara, Jakarta. 